\title{
Is Caesarean Myomectomy a Safe Procedure? A Comparative Study
}

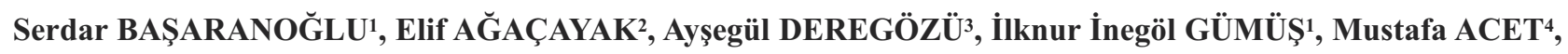 \\ Talip GÜL $\mathbf{L}^{2}$
}

Istanbul, Turkey

\begin{abstract}
OBJECTIVE: Uterine myomas are the most common benign pelvic tumours observed during the reproductive period.Increased risks of haemorrhage and postoperative morbidity lead professionals to avoid myomectomy at the time of Cesarean (C-section). The present study retrospectively analysed the data of patients who had undergone C-section only and those that had undergone C-section and simultaneous myomectomy.
\end{abstract}

STUDY DESIGN: The data of 42 patients (Group 1) who had underwent caesarean myomectomy and of 50 patients underwent C-section only (Group 2) out of 92 patients that had been taken into C-section on the basis of obstetric indications were retrospectively analysed in this study. The relevant patient data were recorded with the inclusion of demographic data, gestational week, and preoperative and postoperative laboratory findings. Types, locations and sizes (the largest diameter) of individual myomas were identified and noted.

RESULTS: The mean diameter of myomas was $66.3 \pm 30.2 \mathrm{~mm}$. Ten patients that had underwent caesarean myomectomy $(23.8 \%)$ developed a need for intensive care. No statistically significant difference was found in laboratory parameters between Group 1 and Group 2.

CONCLUSION: Caesarean myomectomy, when performed by experienced obstetricians, does not lead to a significant increase in maternal morbidity and mortality. Although the short-term effects of this procedure are known, there is a need for the conduct of more comprehensive studies to establish its longterm effects on fertility or how it will affect the next pregnancy processes.

Keywords: Pregnancy, Cesarean, Myomectomy, Morbidity

Gynecol Obstet Reprod Med 2016;22:1-4

\section{Introduction}

Uterine myomas are the most common benign tumours of the uterus and female genital system. Their incidence in pregnancy varies between 2.7 and $12.6 \%$ and increases with gestational week. ${ }^{1,2}$ As the age at conception and rate of C-section are on an increasing trend, obstetricians' frequency of observing myomas during $\mathrm{C}$-section is also increasing. Uterine my-

${ }^{1}$ Fatih University Faculty of Medicine Department of Obstetrics and Gynecology, Istanbul.

${ }^{2}$ Dicle University Faculty of Medicine Department of Obstetrics and Gynecology, Diyarbakur.

${ }_{3}^{3}$ Bahçelievler State Hospital Obstetrics and Gynecology, Istanbul.

${ }^{4}$ Medipol University Faculty of Medicine Department of Obstetrics and Gynecology, Istanbul.

Address of Correspondence: Serdar Başaranoğlu Fatih University Faculty of Medicine Department of Obstetrics and Gynecology, Istanbul. drsbasaran@gmail.com.tr

Submitted for Publication: 02.10 .2015

Accepted for Publication:

06.11 .2015 omas are usually asymptomatic during pregnancy, but may occasionally result in obstetric complications. This spectrum includes; the location and size $(>5 \mathrm{~cm})$ of the myoma that frequently presents with abortion, malpresentation, placental abruption, intrauterine growth restriction (IUGR), placenta previa, abnormal placental invasion, preterm labour, preterm rupture of membranes (PROM), post-partum haemorrhage or bleeding requiring blood transfusion..$^{3,4}$ Caesarean myomectomy is avoided due to its fertility-reducing effects, including excessive post-partum bleeding and the resulting hysterectomy to control bleeding. ${ }^{5}$ Specifically for myomas located in the lower segment or the posterior wall of the uterus, myomectomy is recommended to be performed right after the $\mathrm{C}$ section. ${ }^{6}$ In recent years, studies undertaken with large series of patients to compare patients operated with myomectomy at the time of C-section to those that were operated with $\mathrm{C}$-section only demonstrated that myomectomy at the time of C-section did not increase the risk of intraoperative haemorrhage or uterine atony. ${ }^{7,8}$ The present study aimed to identify and compare the maternal, demographic, clinical, laboratory and surgical findings belonging to patients that had and had not undergone myomectomy at the time of $\mathrm{C}$-section. 


\section{Material and Method}

A total of 92 patients admitted to our clinic between January 2010 and December 2014 were included in this study. The study group consisted of 42 patients that had been taken into $\mathrm{C}$-section on the basis of different obstetric indications and underwent simultaneous myomectomy (Group 1), whereas the control group was composed of 50 patients with similar clinical and laboratory findings that had been taken into C-section for delivery at our clinic between the same time, but had not been subjected to any other surgical procedures (Group 2). In both groups, patients with multiple pregnancies, placental abruption, abnormal placental invasion, bleeding-clotting disorders, HELLP syndrome and immune thrombocytopenic purpura (ITP) as well as patients with a history of medicinal therapies causing bleeding disorders (aspirin, heparin, LMWH, warfarin, etc.) and any additional surgical procedure other than intraoperative myomectomy were excluded from the study. At the time of presentation, certain data relating to the patients were recorded with the inclusion of age, gravida, parity, gestational week and myomas identified during C-section (type, location and size - the largest diameter). The patients were then evaluated in terms of preoperative and postoperative haemoglobin $(\mathrm{Hb})$ and haematocrit (Htc) levels, need for blood transfusion, postoperative obstetric complications, need for intensive care and pathological diagnoses. The data pertaining to the patients were obtained from files and electronic records of the hospital. Before initiation of the study, due approval was obtained from the Local Ethics Committee of Dicle University.

Myomectomy Technique: Once the baby had been delivered, 60-90 drops $/ \mathrm{min}$ of $30 \mathrm{IU}$ oxytocin in $100 \mathrm{ml}$ dextrose was administered to the patient, and this was followed by a linear incision on the myoma with electrocautery. Following the removal of the myoma from its pseudo-capsule, the myometrial bed was closed off with absorbable sutures. The serosa was closed off with absorbable sutures of 2-0 or 3-0 diameter. With bleeding taken under control, all patients were put on prophylactic antibiotic regimens in the postoperative period.

Statistical analyses were undertaken with Statistical Package for Social Sciences for Windows 15.0 (SPSS Inc., Chicago, IL, USA) and Excel as software. The KolmogorovSmirnov test was used to establish whether or not numeric data exhibited a normal distribution, and the percentage was expressed as mean + standard deviation. Data demonstrating a normal distribution were analysed with the Student-t test. For the results thusly obtained, 95\% confidence interval and $p<0.05$ were regarded as preconditions for statistical significance.

\section{Results}

The present study included 42 patients (Group 1) and 50 control subjects (Group 2) amounting in total to 92 patients. Data on age, gravida, parity, gestational week and preoperative and postoperative hemogram levels of the patients and control subjects were demonstrated in Table 1. In this respect, no statistically significant difference was found between the two groups. The mean diameter of the removed myomas was $66.3 \pm 30.2 \mathrm{~mm}$ (40-150). Sizes, locations and types of myomas were given in Table 2. Myomas were generally subserous and most commonly had a diameter of $\leq 5 \mathrm{~cm}$. They were most frequently localised in fundus, corpus or fundus and corpus. Indications of patients undergoing cesarean myomectomy were given in Table 3. A review of the groups led to the finding that none of the myomectomy patients had required additional gynaecological operations, including hysterectomy. It was further identified that 10 of the patients in Group 1 (23.8\%) had developed a need for intensive care in the preoperative period, but none of the patients had required blood transfusion. Considering the histopathologic diagnoses of the patients that had undergone myomectomy, it was established that leiomyoma had been reported in 38 patients and degenerated leiomyoma in 4 patients.

Table 1: Demographic data, preoperative and postoperative laboratory parameters of the patients

\begin{tabular}{lccc}
\hline & $\begin{array}{c}\text { Group 1 (n:42) } \\
\text { mean } \pm \text { SD }\end{array}$ & $\begin{array}{c}\text { Group 2 (n:50) } \\
\text { mean } \pm \text { SD }\end{array}$ & $\begin{array}{c}\mathrm{p} \\
\text { value }\end{array}$ \\
\hline Age & $32.8 \pm 5.3$ & $30.9 \pm 3.6$ & 0.056 \\
Gravidy & $3.7 \pm 1.9$ & $4.4 \pm 1.9$ & 0.080 \\
Parity & $2.4 \pm 1.9$ & $3.0 \pm 1.9$ & 0.109 \\
Gestational age (w) & $35.5 \pm 3.9$ & $36.5 \pm 2.2$ & 0.262 \\
Preoperative Hb & $12.03 \pm 1.51$ & $11.24 \pm 1.69$ & 0.050 \\
Post-operative Hb & $10.50 \pm 1.33$ & $10.32 \pm 1.36$ & 0.717 \\
Preoperative Htc & $35.52 \pm 3.64$ & $35.94 \pm 5.01$ & 0.655 \\
Post-operative Htc & $30.95 \pm 3.99$ & $32.76 \pm 3.64$ & 0.020 \\
\hline
\end{tabular}

Hb: Haemoglobin, Htc: Haematocrit, SD: Standard deviation, Student- $t p<0.05$ significant 
Table 2: Fibroids types, diameter and locations

\begin{tabular}{lr}
\hline Types & $\mathrm{n}(\%)$ \\
Pedunculated & $5(11.9)$ \\
Subserous & $33(78.6)$ \\
Intramural & $3(7.1)$ \\
Submucosal & $1(2.4)$ \\
Diameter & \\
$\leq 5 \mathrm{~cm}$ & $24(57.1)$ \\
$>5 \mathrm{~cm} .<10 \mathrm{~cm}$ & $13(30.9)$ \\
$\geq 10 \mathrm{~cm}$ & $5(11.9)$ \\
Locations & \\
Fundus & $9(21.4)$ \\
Corpus & $17(40.5)$ \\
Lower uterine segment & $7(16.7)$ \\
Posterior & $6(14.3)$ \\
Fundus+corpus & $3(7.1)$ \\
\hline
\end{tabular}

Table 3: Indications of patients undergoing cesarean myomectomy (CM)

\begin{tabular}{lrc}
\hline Indications & $\mathrm{n}(42)$ & $\%$ \\
\hline Previous cesarean & 12 & 28.6 \\
Malpresentation (breech, transverse, oblique) & 7 & 17.5 \\
CPD & 5 & 11.9 \\
Treatment of pregnancy (IVF, IUI) & 3 & 7.1 \\
Previous uterine surgery & 4 & 9.5 \\
Fetal distress & 3 & 7.1 \\
Unprogressive labor & 3 & 7.1 \\
Maternal request & 2 & 4.8 \\
Multiple pregnancy & 2 & 4.8 \\
Abruptio placenta & 1 & 2.4 \\
\hline
\end{tabular}

CPD: Cephalopelvic disproportion, IVF: In-vitro fertilization, IUI: Intra-uterine insemination

\section{Discussion}

Increased oestrogen levels create a tendency for myomas to grow during pregnancy; however, myomas decrease in size in the post-partum period. ${ }^{9}$ Myomectomy at the time of C-section is one of the currently debated matters in the field of obstetrics due to the risks of bleeding and the resulting hysterectomy. Recently, large-scale studies indicated that caesarean myomectomy could be safely performed in specifically selected cases (subserous, pedunculated or small-diameter myomas $<5 \mathrm{~cm}$ ). Patients who did not underwent myomectomy may later present with preterm labour, early delivery, intrauterine growth restriction, morbidly adherent placenta and post-partum bleeding. Shavell et al. reported that pregnant women with myomas exceeding $5 \mathrm{~cm}$ in diameter were at a higher risk compared to patients with smaller or no myomas. ${ }^{4}$ Studies undertaken in recent years came to the conclusion that bleeding was not excessive and the procedure was safe if the caesarean myomectomy was undertaken by experienced sur- geons. ${ }^{10,11}$ In Turkey, Ortac et al. ${ }^{12}$ reported no bleeding and no need for blood transfusion in patients with myomas exceeding $5 \mathrm{~cm}$ that had been operated with caesarean myomectomy. Kaymak et al. ${ }^{13}$ reported for a sample of 40 patients that 5 patients had developed haemorrhage, but this finding was not statistically significant when compared to the control group.Another study comparing 111 patients that had undergone caesarean myomectomy to 275 pregnant women that had undergone $\mathrm{C}$-section only found no case that had been subject to hysterectomy and no significant difference between the groups in terms of preoperative and postoperative haematocrit (Hct) change and incidence of haemorrhage. ${ }^{14}$ When the preoperative and postoperative haemoglobin $(\mathrm{Hb})$ and haematocrit (Hct) levels of the patients in the present study were compared, no statistically significant difference was observed between the two groups. The recommendations for the reduction of bleeding during myomectomy in the intraoperative process included the administration of high doses of oxytocin, uterine tourniquet, bilateral uterine arterial ligation and the use of electrocautery/argon-beam coagulator. ${ }^{15,16}$ All patients in our study underwent myomectomy with the use of electrocautery and a standard dose of oxytocin during the procedure. Furthermore, it was found that no patient had been subject to the use of tourniquet or uterine arterial ligation. A look at the literature indicates that the length of operation is longer and blood loss is higher in caesarean myomectomy compared to $\mathrm{C}$-section only. The present study could not obtain data on the length of operation, but experience shows that the length of operation will be longer in caesarean myomectomy. Kwon et al. ${ }^{17}$ conducted a study to compare caesarean myomectomy patients with myomas $>5 \mathrm{~cm}$ to those with myomas $\leq 5 \mathrm{~cm}$ in terms of preoperative and postoperative haemoglobin changes, length of hospital stay, postoperative fever and length of operation and found no significant difference between the groups. Park et al..$^{5}$ compared 97 pregnant women who underwent caesarean myomectomy and 60 pregnant women with myomas that had undergone $\mathrm{C}$-section only and identified no complications that were independent from the location of the myoma. And they reported that myomectomy could be safely performed at the same time of C-section. The majority of the patients included in our study $(78.6 \%)$ had subserous myomas, which were mainly localising in the fundus $(21.4 \%)$, corpus $(40.5 \%)$ or fundus + corpus $(7.1 \%)$. A review of the literature shows that size of the myoma matters in caesarean myomectomy patients, but does not exhibit any cutoff value for this assessment. Studies on the safety of removal of myomas $\geq 5 \mathrm{~cm}$ during $\mathrm{C}$-section reported no difference between the groups in length of hospital stay, $\mathrm{Hb}$ changes and length of operation. ${ }^{18,19}$ The mean diameter of myomas in our study was $66.3 \pm 30.2 \mathrm{~mm}$. Among the operated patients, 24 (57.1\%) had myomas with diameters $\leq 5 \mathrm{~cm}, 13$ (30.9\%) with diameters between $>5 \mathrm{~cm}$ and $<10 \mathrm{~cm}$, and $5(11.9 \%)$ with diameters $\geq 10 \mathrm{~cm}$. Furthermore, none of these patients with different sizes of myomas exhibited haemorrhage or a need for 
blood transfusion. The histopathological examination of the removed myoma materials revealed that all the materials were of benign character. Although short-term morbidities of caesarean myomectomy are known, there are not sufficient data regarding its effects on long-term fertility or the complications that may emerge in further pregnancies. ${ }^{20}$

In conclusion, considering the results of this study together with the knowledge in the literature, we think that performance of myomectomy during $\mathrm{C}$-section will not lead to a significant increase in maternal morbidity and mortality in the hands of experienced obstetricians, regardless of the size and location of the myoma. However, even though the short-term effects of this procedure are known, the literature does not provide sufficient data on its effects on endometrial and myometrial functions. Therefore, we believe that further studies are needed on how caesarean myomectomy affects the following maternal processes to gain deeper understanding of the safety of this procedure.

\section{References}

1. Laughlin SK, Baird DD, Savitz DA, Herring AH, Hartmann KE. Prevalence of uterine leiomyomas in the first trimester of pregnancy: an ultrasound-screening study. Obstet Gynecol 2009;113(3):630-5.

2. Exacoustòs C, Rosati P. Ultrasound diagnosis of uterine myomas and complications in pregnancy. Obstet Gynecol 1993;82(1):97-101.

3. Klatsky PC, Tran ND, Caughey AB, Fujimoto VY. Fibroids and reproductive outcomes: a systematic literature review from conception to delivery. Am J Obstet Gynecol 2008;198:357-66.

4. Shavell VI, Thakur M, Sawant A, Kruger ML, Jones TB, Singh M, et al. Adverse obstetric outcomes associated with sonographically identified large uterine fibroids. Fertil Steril 2012;97:107-10.

5. Park BJ, Kim YW. Safety of cesarean myomectomy. J Obstet Gynaecol Res 2009;35(5):906-11.

6. Kwawukume EY. Myomectomy during cesarean section. Int J Gynecol Obstet 2002;76:183-4.

7. Ma PC, Juan YC, Wang ID, Chen CH, Liu WM, Jeng CJ. A huge leiomyoma subjected to a myomectomy during a cesarean section. Taiwan J Obstet Gynecol 2010;49:220-2.

8. Tinelli A, Malvasi A, Mynbaev OA, et al. The surgical outcome of intracapsular cesarean myomectomy: a match control study. J Matern Fetal Neonatal Med 2014;27:6671.

9. Başaranoğlu S, Gül T. Miyoma Uterinin Kliniği ve Semptomlar1. T Klin J Gynecol Obst-Special Topics 2014;7(2): $18-23$.

10. Sapmaz E, Celik H, Altungul A. Bilateral ascending uterine artery ligation vs. Tourniquet use for hemostasis in cesarean myomectomy: a comparison. J Reprod Med 2003; 48:950-4.

11. Li H, Du J, Jin L, Shi Z, Liu M. Myomectomy during cesarean section. Acta Obstet Gynecol Scand 2009;88:183-6.

12. Ortac F, Güngör M, Sönmezer M. Myomectomy during cesarean section. Int J Gynecol Obstet 1999;67:189-90.

13. Kaymak O, Ustunyurt E, Okyay RE, Kalyoncu S, Mollamahmutoglu L. Myomectomy during cesarean section. Int J Gynecol Obstet 2005;89:90-3.

14. Roman AS, Tabsh KM. Myomectomy at time of cesarean delivery: a retrospective cohort study. BMC Pregnancy Childbirth 2004;4(1):14.

15. Kwawukume EY. Cesarean myomectomy. Afr J Reprod Health 2002;6:38-43.

16. Topçu HO, İskender CT. Timur H. Kaymak O. Memur T. Danışman N. Outcome safter cesarean myomectomy versus cesarean alone among pregnant women with uterine leiomyomas. Int J Gynecol Obstet 2015;130(3):244-46

17. Kwon DH, Song JE, Yoon KR, Lee KY. The safety of cesarean myomectomy in women with large myomas. Obstet Gynecol Sci 2014;57(5):367-72.

18. Incebiyik A, Hilali NG, Camuzcuoglu A, Vural M, Camuzcuoglu H. Myomectomy during caesarean: a retrospective evaluation of 16 cases. Arch Gynecol Obstet 2014;289(3):569-73.

19. Lee JH, Cho DH. Myomectomy using purse-string suture during cesarean section. Arch Gynecol Obstet 2011;283 (Supp 11):35-7.

20. Güney M, Oral B, Özsoy M, Mungan T. Sezaryen esnasında myomektomi: retrospektif matermal sonuçların değerlendirilmesi. SDÜ Tip Fak Derg 2007;14(1):1-4. 